\title{
ON PINEL'S MAGNETIC WATER GAUGE FOR STEAM BOILERS.
}

By Mr. GEORGE PIGGOTT, OF BIRMTnghaM.

Most appliances for indicating the height of water in steam boilers are liable to be inefficient for the purpose, chiefly from undue friction caused by the buoy rod passing through a stuffing box or packed joint: the packing is often so tight that the float will not move the rod; and if it is packed lightly to dispense with the friction, then there is a leakage of steam which is very objectionable. The Magnetic Water Gange described in the present paper, the invention of $M$. Pinel of Rouen, is free from these objections : the chief points to be noticed are, its compactness and simplicity, and the facility of fixing, its exactness in working, and durability, and the very little attention required to keep it in working order.

The gange is shown in Figs. 1, 2, and 3, Plate 15, and consists of an upright cast iron pipe $A$, on the top of which is fixed a brass box $B$ square in section, as shown in the plan, Fig. 3. A hollow cylindrical float $\mathrm{C}$ proved to stand a pressure of 10 atmospheres is attached to an iron rod $\mathrm{D}$, passing through the bush $\mathrm{E}$ without any packing, and also through the guide $F$, perfectly easy and free. To the upper end of this rod is fixed a strong horse-shoe magnet $G$, shown enlarged in Figs. 4 and 5 , the poles being bent forwards at right angles to the body of the magnet, which falls or rises in the brass box $B$ with the fall or rise of water in the boiler. On the exterior face of the box is an isolated iron needle, held merely by the attraction of the poles of the magnet, which it follows in all its movements, rolling on the face of the box as the magnet rises or falls according to the height of water in the boiler. The face of the box is silvered and graduated, so that the least movement of the needle is perceptible: it is covered with glass to protect it from dust and injury. On the side of the upright 
pipe A a shrill whistle $H$ is fixed, closed by a valve kept shut by the internal pressure of steam : when the float is nearly at the lowest limit of its range, a small stud $I$ on the rod $D$ presses on a lever which immediately opens the valve and allows the steam to sound the whistle; this at once makes known the want of water.

The fixing of the gauge is exceedingly simple, and does not allow any leakage of steam, which is not only a waste but often injures the plates of a boiler. A hole about $1 \frac{1}{4}$ inch diameter is drilled in the top of the boiler at the required place, and the gauge is fixed upright, the joint being made with india-rubber and a nut screwed on inside the boiler. The length of the buoy rod is adjusted to suit the height of water it is usual to work at, the float being weighted to sink just half way in the water, so that the adjustment is reduced to a mere matter of measurement; the needle points to zero when the water is at its proper working height, and the water level may then be lowered $2 \frac{1}{2}$ inches before the whistle sounds; but if it exceeds this limit by $\frac{1}{8}$ inch, the whistle will sound the alarm, and will continue to whistle till the water level is raised again. The gauge is sometimes constructed with two whistles, for high and low water. The buoy rod is limited in its motion both upwards and downwards: when the water is raised 6 inches above the proper working height, the coupling of the buoy rod comes in contact with the bush $\mathrm{E}$, which prevents the magnet from being forced against the top of the gauge; and when the water falls more than 3 inches below its proper level, the brass coupling which joins the magnet to the buoy rod rests on the top of the guide $F$, bolding the buoy suspended till the water is raised high enough to float it again : this prevents the magnet from moving out of the brass box. Neither of these cases ought to occur, but the provision is made in case of their occurrence. The brass box is planed on the back and front, and for a portion of the width on each side, forming a guide for the magnet to slide in. On the back of the magnet is fixed a brass bar, bearing only on the planed surface on each side of the box, by which the magnet is made to slide perpendieularly; immediately under this bar a light spring is fixed to the back of the magnet, also bearing only on the back of the box, which keeps the poles of the magnet slightly pressing against the face. 
This water gauge indicates the height of water so exactly and the absence of friction renders it so sensitive that the writer has noticed, when it has been put just over the fireplace of a double-flue boiler with brisk fires going, that the needle rises and falls with the fluctuation of the water caused by the quick ebullition. The gauge requires scarcely any attention, and the inconvenience of constantly greasing and watching that the float acts is entirely done away with. The silvered face is kept clean by washing with soap and water two or three times a year; this is all the attention it requires.

The total number of these gauges now at work is 3500,65 of which are in England and the remainder principally in France; all of which are working with as much accuracy as when first put up, and some of them have now been nine years at work. The rubbing of the magnet against the brass box gives it a polish that renders the wear inappreciable: its magnetic power must necessarily be weakened in time from the effects of rust, and it would then require renewal, but at present its durability has not been impaired in any way. As there is no passage of steam through the gange, the interior is not liable to any incrustation of deposit. Magnetic gauges were put up at the Paris mint in 1855, and have never been touched since that time: they have also been adopted extensively in the French government workshops and in manufactories.

A specimen of the gauge was exhibited, taken to pieces to show the construction.

Mr. W. F. Batho had had three of the gauges at work at a pressure of $30 \mathrm{lbs}$. to $40 \mathrm{lbs}$., the longest for 8 months; no injury had occurred to them, and they continued in good working order. The only danger that could arise would be from the magnet becoming corroded by long exposure to the steam, and in one of the gauges that had been taken down recently and taken to pieces to be examined there was a slight indication of corrosion commencing on the magnet.

Mr. J. RoBisson asked on what part of the magnet the corrosion took place. 
Mr. W. F. Batho said it was on the top of the magnet, where there would always be a little moisture lying from condensation of steam within the gange.

Mr. C. W. Sremens enquired whether there was found to be any deposit within the gauge, to show that water had been carried up into it.

Mr. W. F. BATHo replied that there was nothing but a little moisture from the condensed steam; and the whistle on the gauge showed that it was always full of steam, because the steam sounded it as soon as opened.

Mr. J. B. Neilson thought the magnetic water gange would be very useful, especially for boilers with internal flues where it was so particularly important to know the water level correctly. He thought the hollow float exhibited appeared rather light for working the gange, and that a stone float would be preferable as safer and more durable, if it could be arranged to be counterpoised. He enquired what was the cost of the gange.

Mr. W. F. BAтHo replied that the gauge cost $£ 710$. or $\mathfrak{f 7} 15 s$.

Mr. J. Roвinson observed that there was no stuffing box for the float rod in this gauge, and therefore no friction to be overcome by the float, so that a light float was quite sufficient to work the rod.

Mr. W. Riohardon had used a different construction of magnetic water gauge on a boiler working up to 50 lbs. pressure situated in a forge, where he was afraid of a glass gauge being exposed to injury, and wanted a gauge that would not be too high up to be easily seen. It consisted of a copper float about 7 inches diameter fixed on a lever, the horizontal spindle of which passed freely through the front of the boiler into the casing of the gauge without any stuffing box or packing, and carried at its outer extremity a bar magnet fixed at right angles to the spindle and parallel to the float lever, working within the casing of the gauge: outside the casing was a steel indicating finger, working loosely on a pin in the same centre line as the spindle of the magnet, which showed the height of water on a dial plate. The magnet and indicating finger both rotated on the centre point of their length, so that both were completely balanced and the finger was propelled by each end of the magnet. This gange had now been at work for 18 months and continued perfectly correct; 
when first put ap, immediately over the fire, its sensitiveness was so great from the violent ebullition that the index was very unsteady, and in order to keep the surface of the water quiet a piece of sheet iron had to be fixed horizontally inside the boiler, sufficiently below the surface of the water not to interfere with the range of the float.

Mr. C. W. SiEmens had seen a magnetic water gauge brought over from America about fifteen years ago, similar to the gauge just referred to, having a radial needle worked by a magnet attached to the float, but had not seen it put into operation.

Mr. G. F. Montz observed that there was one advantage in the magnetic gauge described in the paper, that if the magnet ever got out of order and lost its power the needle would drop down to the bottom of the face, and it would become erident that the gange was not in working order ; but in most gauges having a finger, the finger did not drop when the gauge got out of order, but remained pointing to the dial and apparently indicating the water level.

Mr. E. A. Cowpen thought the principle of the magnetic gauge was a good one, as it did away with the friction of the stuffing box required in ordinary gauges, which was always liable to be packed too tight and check the action of the gauge. One advantage in the construction of the gauge now shown was that the needle was made with a small ring round it at each end, so as to roll on the face instead of sliding, which made its motion very easy.

Mr. F. J. Bramwell remembered a magnetic gauge being proposed by Du Trembley several years ago, having a magnet working inside a tube with a ring attracted by it on the outside, but there would be more friction with a ring than with the rolling needle of the gange now shown.

Mr. C. MAY remarked that if a glass tube were fixed on the top of the gange and could be kept clean, the top of the float rod itself might be seen working within it, and there would be no need of a magnet or an external ring.

A vote of thanks was then passed to Mr. Piggott for his paper.

The meeting then terminated. 
MAGNETIC WATER GAUGE.

Plate 15.

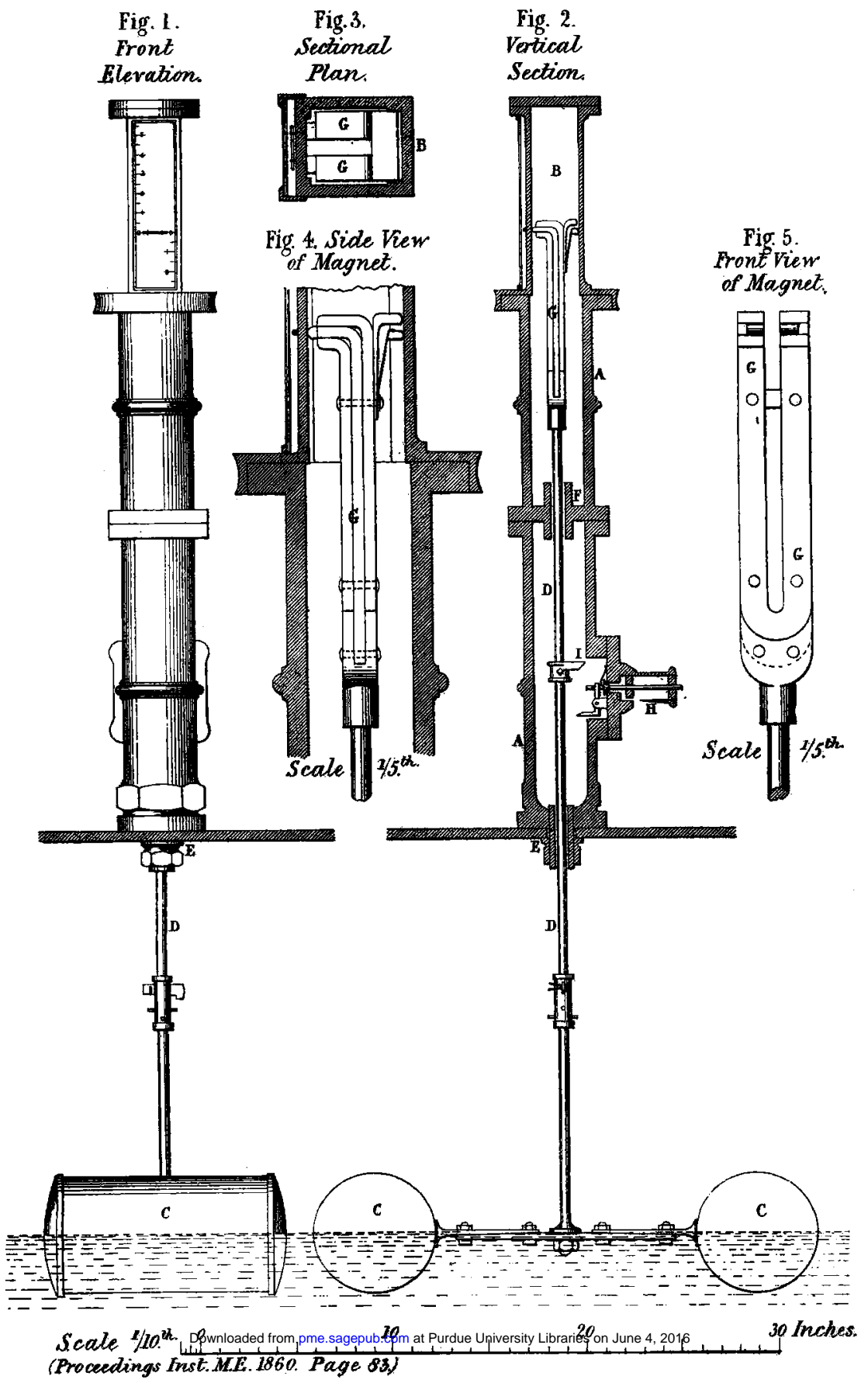

